\title{
ORALIDADE POÉTICA E ENSINO DE LITERATURA: DIFICULDADES CONCEITUAIS, METODOLÓGICAS E PRÁTICAS QUE ENVOLVEM AS POÉTICAS ORAIS
}

\author{
ORALITY POETRY AND LITERATURE EDUCATION: DIFFICULTIES CONCEPT, \\ METHODOLOGY AND PRACTICES INVOLVING THE ORAL POETICS
}

\author{
Gláucia Helena Braz \\ Universidade Federal de Uberlândia
}

\begin{abstract}
RESUMO: Neste estudo, realizamos reflexões acerca das poéticas orais e sua performance no espaço formal de educação e cultura. Objetivamos descrever, analisar e fundamentar os procedimentos teóricos e práticos aplicados ao trabalho com a poesia oral, e ainda, verificar algumas de suas contribuições na formação leitora do indivíduo. Nesse intuito, levantamos inicialmente a problemática conceitual e prática dos pesquisadores e profissionais que trabalham com a oralidade. Recorremos às concepções teóricas de estudiosos como: Zumthor (2007), Ferreira (2010), Fares (2010), Feitosa (2008), Todorov (2009) dentre outros. Apresentamos também os resultados de uma pesquisa realizada em 2011, com um grupo de professores de Uberlândia - MG, atuantes na área de Língua Portuguesa, sobre o ensino de Literatura na rede pública. Por meio desta pesquisa e dos estudos realizados pudemos constatar que esse ensino ocorre, muitas vezes, de forma ineficiente. Apesar dessa constatação, concluímos que metodologias voltadas para a oralidade poética e sua performance, quando utilizadas de forma sistemática e adequada, contribuem significativamente no processo de formação de leitura do aluno. Portanto, as poéticas orais em performance poderiam ser mais valorizadas, e de fato utilizadas no contexto escolar.
\end{abstract}

PALAVRAS-CHAVE: oralidade poética; ensino; literatura; metodologia; dificuldades.

ABSTRACT: In this study, we conducted reflections on the oral poetry and his performance in the educational space and culture. We aimed to describe, analyze and explain the theoretical and practical procedures applied to work with oral poetry, and even check some of their contributions in the reader's individual training. To that end, initially raised the conceptual and practical problems of researchers and professionals working with orality. Use the theoretical concepts of scholars as Zumthor (2007), Ferreira (2010) Fares (2010), Feitosa (2008), Todorov (2009) among others. We also present the results of a survey conducted in 2011 with a group of teachers Uberlândia - MG, working in the Portuguese area, on the teaching of literature in public. Through this research and studies we found that this teaching is often inefficiently. In spite of this, we conclude that methodologies aimed at poetic orality and its performance when used in a systematic and proper manner, contribute significantly in the student reading training process. Therefore, oral poetry in performance could be more valued, and in fact used in the school context.

KEYWORDS: poetic orality; education; literature; methodology; difficulties.

\section{Introdução}

Em pleno século XXI, deparamo-nos com a presença da oralidade em diversas instâncias sociais da cultura moderna, frequentemente associada a várias linguagens 


\section{Revista do SELL}

v. 5 , no. 2

ISSN: $1983-3873$

como a visual, a musical, a cênica, dentre outras. A recorrência desse uso deve-se, provavelmente, ao fato de que a voz transmite uma maior alteridade à mensagem que veicula ao receptor, seja para fins educacionais, jurídicos, mercadológicos ou políticos. Muitas vezes voltada para o utilitarismo, é comum que essa voz seduza as pessoas, levando-as ao consumismo desenfreado ou a escolhas equivocadas, que podem constituir uma espécie de "armadilha" contemporânea, ditada pela força da palavra oral.

Por outro lado, emerge em nossa cultura uma outra voz que não se sujeita ao consumismo nem a ideologias, pois ela emancipa o sujeito: a voz poética. Esta voz traduz os anseios da chamada "cultura das bordas", expressão criada por Ferreira (2010), a qual abarca a voz daqueles que ocupam, frequentemente, a periferia de segmentos institucionalizados, trazendo-os para o centro dos debates hoje realizados nas academias.

O termo "cultura das bordas" implica uma pertença múltipla "daquilo que pode estar nas beiras de sistemas". Isso por que

[...] em espaços não consagrados do mundo urbano, se desenrola toda uma cultura que absorve e é absorvida, criando regiões imantadas que nos permitem pensar em temas, autores, textos a pedir sempre novos parâmetros de avaliação, em regime de movimento e descobertas (FERREIRA, 2010, p. 12-13).

Diante desse conceito, podemos afirmar que o objeto de nosso estudo, as poéticas orais, assim como várias manifestações artísticas que pautam seus repertórios na oralidade - "cinema, música, universos pop, populares em direcionamento midiático, inserções radiofônicas, gêneros variados e aceites, situações narrativas ou teatralizastes" - fazem parte desse "texto-universo" que Ferreira (2010, p. 16) chama "bordas". Incluímos neste espaço a Literatura em geral, e de modo especial a poesia, que ocupa um restrito lugar nos currículos escolares brasileiros, apesar de já se manifestar nos eventos socioculturais de nosso país.

Antônio Cândido (2004) pontua a importância da Literatura, afirmando ser esta arte essencial ao equilíbrio psíquico das pessoas e da própria sociedade, correspondendo, portanto, a uma necessidade universal do ser humano. Constitui, pois, um direito do indivíduo, em qualquer fase da vida, principalmente na época escolar, quando o jovem pode consolidar a sua formação como leitor. Mas as pesquisas metodológicas que despontam atualmente sobre o ensino da disciplina constatam que esta tem recebido um tratamento equivocado por grande parte dos educadores. 


\section{Revista do SELL}

v. 5 , no. 2

ISSN: $1983-3873$

No presente artigo - que constitui parte da pesquisa de Mestrado ${ }^{1}$ concluída em 2012 - levantamos inicialmente a problemática conceitual e prática dos pesquisadores e profissionais que trabalham com a oralidade. Na sequência, procuramos refletir sobre as poéticas orais e sua performance no espaço formal de educação e cultura bem como sobre a importância dessas poéticas na formação leitora do aprendiz.

\section{Dificuldades conceituais, metodológicas e práticas que envolvem as poéticas orais}

Em muitos países, inclusive no Brasil, os "textos de tradição oral e popular são frequentes, tanto nos circuitos letrados, como no cotidiano de cada um de nós, seja na forma de conto, provérbio, máxima, dito popular, trova, cordel etc". (FARES, 2010, p. 264). Entretanto, certo desconforto instaura-se, geralmente, no percurso dos pesquisadores acadêmicos, ao investigarem temas referentes às poéticas orais. Para esses estudiosos, constitui um desafio tratar de tais temas e de toda gama de poetas que se utilizam da voz como principal meio de expressão.

Tal desafio foi comprovado no I Seminário Brasileiro de Poéticas Orais em 2010, que reuniu vários estudiosos da oralidade, em Londrina, no Paraná. Nessa ocasião, constatamos a resistência nas universidades, por parte dos pesquisadores mais convencionais dos estudos literários, em conceder ao texto oral ou às poéticas orais o status de objeto literário. Sendo assim, ocorre no meio acadêmico em geral

[...] de modo sub-reptício, uma tentativa de deslegitimar a pesquisa em si, pois não sendo tomado como "literatura escrita", é inferido, automaticamente, um valor depreciativo ao texto, e negam-Ihe seu valor poético. Daí decorrem denominações pejorativas tais como: "paraliteratura", "subliteratura", "literatura de analfabetos", entre outras. Tal perversidade ratifica 0 mito da supremacia do escrito sobre 0 oral (FERNANDES; LEITE, 2007, p. XII).

\footnotetext{
1 Trata-se da dissertação intitulada $A$ performance do leitor diante da oralidade poética: passagens de indecisão (2012), realizada sob a orientação da professora Dr ${ }^{\mathrm{a}}$ Maria Auxiliadora Cunha Grossi, cujo tema aborda a oralidade poética não só nos espaços formais, como também nos espaços informais de educação e cultura, em Uberlândia - MG.
} 


\section{Revista do SELL}

v. 5 , no. 2

ISSN: $1983-3873$

Apesar da incompreensão e do desconhecimento que se verifica na academia, ainda hoje, diante de um objeto estético que foge às normas impostas pelo cânone, muitos esforços são feitos para que essa área de estudo seja desenvolvida no país. Isso se comprova tendo em vista as pesquisas restritas à Antropologia e ao folclore que, atualmente abrem espaços em algumas instituições e em alguns campos de estudo para a matéria oral. Dentre essas instituições, destaca-se a Associação Nacional de PósGraduação e Pesquisa em Letras e Linguística - ANPOLL - que abriga o Grupo ${ }^{2}$ de Trabalho de Literatura Oral e Popular, um dos mais importantes movimentos de pesquisadores das poéticas orais no Brasil.

Dessa forma, colocado em foco, timidamente, a partir do século XVIII, o estudo dos fatos de cultura oral traz um número considerável de pesquisas e polêmicas, muitas vezes, "incompatíveis e contraditórias que se desenvolveram à margem do que é transmitido pelo ensino geral e, salvo exceções, com o desconhecimento ou o desdém dos que praticam a literatura" (ZUMTHOR, 1997, p. 21).

Diante desta realidade, o conceito "cultura das bordas", introduzido no Brasil por Ferreira (2010), é bastante pertinente, pois soluciona alguns impasses e nomenclaturas equivocadamente utilizadas para caracterizar a oralidade, tais como o de margens ou cultura periférica, relegando frequentemente a oralidade ao folclore e ao popular. A autora reafirma a dificuldade conceitual que envolve também a palavra "folclore" e pontua duas diferentes posturas adotadas pelos pesquisadores:

Há os estudiosos ou apreciadores que segmentam e assumem, por exemplo, o campo literário como um todo de fronteiras rígidas, apegandose a uma certa fixidez e até, por hábito, preferem chamar paraliteratura qualquer outra coisa que pareça fugir ao padrão estabelecido pela instituição "Literatura" ou, no polo oposto, aquilo o que não caiba nos domínios legitimados de uma cultura popular tradicional que se costuma delimitar enquanto Folclore, por sua vez, matéria tornada nobre e justificada. Há, no entanto, quem considere, e que despreze mesmo esses textos de cultura, por não lhes encontrar valor (FERREIRA, 2010, p.12).

Dificuldade conceitual semelhante ocorre com o vocábulo "popular", associado à cultura, literatura, poesia e canção - adjetivo, particularmente, confuso, sendo

\footnotetext{
${ }^{2}$ Esse grupo foi idealizado, em 1982, por Jerusa Pires Ferreira, Bráulio do Nascimento e Idellete Muzart, embora tenham identificado o descaso com o qual a proposta de trabalho sobre literatura oral e popular foi recebida no país, por volta de 1980 (FERNANDES; LEITE, 2007).
} 


\section{Revista do SELL}

v. 5 , no. 2

ISSN: $1983-3873$

considerado como uma manifestação "anônima e nascida espontaneamente no seio das massas, adotada pelo povo que dela se apropriou" (ZUMTHOR, 1997, p. 24). Essa conotação social remete-nos, ainda, a um postulado preconceituoso, vinculado à ideia de folclore, de uma diferença no tempo, no espaço ou nas configurações culturais, que classifica o movimento histórico como uma estrutura social ou uma forma de discurso que perde, progressivamente, sua função - o preconceito que Zumthor denomina "folclorizante".

Ferreira (apud AMARANTE, 2002, p. 11) não considera a cultura popular como folclore, porque isso desprezaria a constante transformação do fenômeno e significaria considerá-lo de forma sincrônica e homogênea. A autora concebe a existência de uma circularidade cultural em nossa sociedade, ou seja, que sempre ocorre no fenômeno da comunicação: o "ouvir, dizer, repetir, escrever, tornar a dizer e contar, [...] recriar". Nessa circularidade, a existência de uma arte popular é determinada através do conceito de classe social, pois são os mecanismos socioeconômicos que vão originar diferentes necessidades culturais.

Ferreira (1985) destaca também que a relação entre o fato popular e o não popular é que os constitui, que cada cultura possui sua especificidade, sendo compartilhada, enquanto gosto e tendência geral, por determinado grupo, como é o caso da cultura tradicional nordestina. Todavia, a pesquisadora considera que tanto as culturas tradicionais eruditas como as populares têm, na sociedade, seus espaços e suas possibilidades, em permanente transformação, não havendo, portanto, uma cultura "superior" a outra.

Ao defender o binômio - o popular e o erudito - Ferreira (1985) reafirma que as diferenças sociais e individuais, presentes no fenômeno cultural, englobam dimensões bastante complexas da memória e da transmissão em um repertório que está sendo transmitido do mesmo modo, tanto na cultura popular como na erudita. Mesmo porque, na atualidade, conforme pontua Agra (2010) ${ }^{3}$ "são comuns os trânsitos inesperados entre repertórios tidos como exclusivos que são rapidamente assimilados [...] e que retornam ao circuito como novas e inventivas formas de operar o jogo". Esses trânsitos comprovam a circularidade do conceito de cultura e, de certa forma, a inadequação da ideia de margem aliada ao termo, pois os fatos culturais não mais constituem um fenômeno à parte na

\footnotetext{
${ }^{3}$ Essa citação foi retirada da "orelha" do livro Cultura das Bordas (AGRA, 2010).
} 


\section{Revista do SELL \\ v. 5 , no. 2 \\ ISSN: $1983-3873$}

sociedade. Estão sim inseridos no meio social, onde se misturam, cada vez mais, o popular e o erudito, o escrito e o oral, a periferia e o centro.

Nesse viés, Bordini (2006) dialoga com as concepções de Ferreira (1985) ao destacar que a existência de múltiplas culturas, proliferando lado a lado em uma velocidade eletrônica, determina uma alteração radical no campo dos estudos literários. Considera, portanto, que o conceito "bordas" tenha uma especial adequação aos tempos pós-modernos, por conseguir abranger tal multiplicidade. Não se trata de margens culturais e, sim, de um deslocamento de segmentos, inseridos em uma cultura, porém, muitas vezes desconsiderados.

Apesar disso, a autora afirma que estamos caminhando para mudanças de concepções neste campo, a partir das pesquisas da chamada Escola de Birmingham. Tais pesquisas, voltadas para a história dos comportamentos do sistema literário quanto à vida cultural e vice-versa, não só reinserem debates sobre o tema na sociedade, mas também, "promovem as manifestações das classes populares e das minorias" (BORDINI, 2006, p. 13).

Desses debates originou-se o conceito de "multiculturalismo", fenômeno que se estende pelo mundo ocidental, a partir da influência da América do Norte e, em especial, dos Estados Unidos, que significa

[...] o reconhecimento de que cultura não é um todo unitário, mas um mosaico de manifestações simbólicas autônomas e específicas, geradas no interior dos diversos segmentos que formam as sociedades, mas capazes de ultrapassar fronteiras nacionais ou regionais. Preside, pois a ideia de diferença e, principalmente, a de que as diferenças podem coexistir pacificamente, sem perder suas características próprias e sem serem dominadas por algum conceito universalista ou humanista que as uniformize (BORDINI, 2006, p. 15).

De certa forma, esse conceito de "multiculturalismo" coincide com o de "bordas", pois ambos consideram o fenômeno cultural em sua contiguidade, um todo, em que se convivem e se comunicam as diferenças. Segundo Bordini (2006), a Literatura sempre esteve nessa mesma direção no campo literário como, por exemplo, na coexistência das diferenças de gêneros, estilos, interpretações, mesmo quando, ao longo 


\section{Revista do SELL}

v. 5 , no. 2

ISSN: $1983-3873$

da História, os estudiosos tenham buscado um conceito unificante para esse processo de contínua renovação.

A busca de um equilíbrio, proposto pelo conceito "bordas", talvez seja o caminho mais adequado para se estabelecer um amplo diálogo entre o "multiculturalismo" e os estudos literários, bem como entre as poéticas da oralidade e a alta cultura. Ressaltamos ainda que, enquanto a História da Literatura continuar sendo apresentada em uma perspectiva "scriptocêntrica", ou seja, que privilegie um cânone de obras escritas, transmitido por meio de uma elite intelectual, a existência das tradições orais e das culturas populares nativas irão permanecer excluídas da historiografia cultural e os estudos das poéticas orais continuarão, ainda, "às bordas" da academia.

Nesse viés, Fares (2010) defende a inclusão das poéticas orais no sistema de ensino brasileiro e considera inaceitável a desvalorização do texto oral, afirmando que

[...] desqualificar este objeto é desconsiderá-lo como texto fundador, a origem de todos os outros [...]. As poéticas orais fazem parte do universo cultural dos discentes, sobretudo os moradores da zona rural do Brasil, das zonas periféricas das grandes cidades, e os que (con)viveram nesses territórios ou com seus habitantes. Trazer esta realidade para o sistema de ensino, estabelecer relações de trocas simbólicas é um dos sentidos da educação. Por isso, a discussão deve também pertencer aos cursos de letras, ao ensino fundamental e ao médio (FARES, 2010, p. 265-266).

A autora (2010) aponta que, na realidade, a presença da oralidade no ambiente escolar ocorre de forma bastante tímida, relegada apenas a datas especiais. Logicamente isto reflete a sua quase ausência nos Cursos de Letras, por sua vez, causada devido a vários fatores, dentre eles:

1) O fato da matéria estar fora do cânone e por isso afastada dos círculos acadêmicos, seja como disciplina ou como conteúdo, e exemplifico com os cursos de graduação em letras [...].

2) Os profissionais da área, normalmente, desqualificam qualquer literaturas ditas das bordas - as de expressões regionais, as direcionadas virtualmente ao público infantil e juvenil, as africanas, as de testemunho etc. as consideram "meio-literárias" ou não literatura - e não promovem o interesse de novas pesquisas no corpo discente.

3) O mito, a lenda e o caso, como ainda se costumam titular o repertório oral, como uma matéria vinda das raízes populares da população, [...] sempre foram muito mais objeto dos antropólogos e dos folcloristas do que dos profissionais das letras (FARES, 2010, p. 264-265). 


\section{Revista do SELL}

v. 5 , no. 2

ISSN: $1983-3873$

Em outras palavras, Fares (2010) afirma que a escola geralmente privilegia as obras canônicas em detrimento daquelas que se caracterizam como orais. Distantes da realidade do aprendiz que ainda não consolidou o hábito de leitura, os textos da chamada "alta cultura" geram desinteresse nos alunos e os afastam da leitura literária. Há, também, um desprestígio das poéticas orais pelos próprios profissionais da área de Letras. Consequentemente estes estudos ficam relegados principalmente aos folcloristas e antropólogos.

Embora haja em algumas faculdades do Brasil a inserção ${ }^{4}$ de temas ligados às literaturas orais e populares, essa inserção também é insuficiente. Seria necessário que todas as universidades do país oferecessem disciplinas voltadas para esta área na Graduação e Especialização em Letras para que esse tema chegasse, de fato, às escolas, contribuindo assim no processo de formação leitora dos indivíduos.

Infelizmente, de acordo com a realidade brasileira, a forma como a disciplina Literatura tem sido oferecida aos jovens, do Ensino básico até a Graduação não inclui a Literatura oral e, muitas vezes, desfavorece o gosto pela leitura. Ao longo da nossa história, percebemos que os alunos de Letras, no Brasil, leram muito pouco de nossos romancistas ou poetas e, por isso, frequentemente não cultivam o gosto pela Literatura. Quando se tornam professores dessa disciplina, forma-se, na educação, um círculo vicioso, visto que comportamentos que desfavorecem a prática da leitura prazerosa são, muitas vezes, cultivados nos discentes. Pesquisas realizadas no meio acadêmico sobre o ensino de Literatura - como, por exemplo, um estudo realizado em algumas escolas de Viçosa - comprovam essa realidade.

Verificou-se que o ensino tradicional da Literatura vigente em escolas de
Ensino Médio [...] é feito com ênfase em aulas expositivas, fundamentadas
em livros didáticos que apresentam uma abordagem cronológica, baseada
em panoramas históricos e características de estilos de épocas, sem se
deter, diretamente, na "leitura" de textos literários. Observou-se ainda a
tendência para um ensino da Literatura abstrato, fragmentado e
desvinculado da realidade do aluno, sem uma análise crítica dos textos e

\footnotetext{
${ }^{4}$ Segundo Fares (2010), as graduações em Letras da Universidade do Estado do Pará (UEPA) e na Universidade da Amazônia (UNAMA), trazem nos seus currículos Literatura infantil um item relacionado à oralidade e Literatura [brasileira] de expressão amazônica em que se privilegia uma unidade sobre essas poéticas. Além disso, cursos de pós-graduação strito sensu em Literatura e Estudos Literários incluem hoje outras abordagens textuais, propõem estudos afins, abrindo margem para estudos comparativos entre oralidade e escrita, entre outros.
} 


\section{Revista do SELL}

v. 5 , no. 2

ISSN: $1983-3873$

autores. A prática mais usual se detém em autores canônicos, para exemplificação de determinada "escola" em que se inserem. (VIEIRA, $2008 . \quad$ Disponível em: <http://professorharlei.blogspot.com.br/2008/12/literatura-no-ensino-mdiouma-anlise.html).

A fragilidade da relação Literatura/ensino tem se revelado, também, no contexto de outros países, como por exemplo, na França, em que, segundo Todorov (2009), é comum, especialmente no Ensino Médio, os programas centralizarem os estudos na História da Literatura, desconsiderando o universo vasto e complexo da própria obra literária, ocorrendo, desse modo, uma concepção restrita da disciplina. Afirma o autor que o ideal seria que os professores interiorizassem o que aprenderam na universidade, mas ao invés de ensinarem esse aprendizado teórico aos discentes, o transformassem em uma ferramenta invisível em suas práticas pedagógicas, implementando, por meio desse suporte, metodologias diferenciadas em sala de aula, a fim de contribuir para a formação leitora dos alunos.

Essa advertência feita por Todorov (2009) à sociedade francesa, parece-nos ser bastante pertinente à realidade brasileira, considerando que os professores do Ensino Básico, em nosso pais, frequentemente, encontram dificuldades em relação à adequação de suas metodologias nas aulas de Literatura. Isso foi comprovado em uma pesquisa que realizamos em maio de 2011, no Centro de Estudos Municipais e Projetos Educacionais CEMEPE, de Uberlândia (MG), ao entrevistarmos um grupo de professores da rede pública de ensino. Na sequência, a título de exemplo, pontuamos aspectos importantes dessa pesquisa.

\section{A oralidade poética na escola: considerações sobre o ensino de Literatura}

Para realizar esta pesquisa, aplicamos, um formulário impresso ${ }^{5}$ contendo algumas questões sobre o ensino de Literatura a 27 professores, atuantes na área de Língua Portuguesa e Literatura do $6^{\circ}$ ao $9^{\circ}$ anos do Ensino Fundamental, na rede pública da cidade de Uberlândia. Na ocasião, percebemos certa resistência por parte de alguns docentes à adesão à pesquisa. Isso possivelmente se deve ao descrédito desses

\footnotetext{
${ }^{5} \mathrm{O}$ formulário aplicado aos professores encontra-se em anexo a este artigo.
} 


\section{Revista do SELL}

v. 5 , no. 2

ISSN: $1983-3873$

profissionais quanto a inovações metodológicas voltadas ao ensino em geral. Tal descrédito, provavelmente advém da incredibilidade desses professores no que se refere às políticas educacionais adotadas nas últimas décadas, pelos órgãos governamentais.

Apesar dessa relativa resistência, os professores participaram da pesquisa, e com a análise dos formulários, comprovamos várias dificuldades por eles encontradas em relação ao desafio de formar leitores, tais como: a falta do hábito de leitura pelos aprendizes; a ausência de incentivo familiar; o grande desinteresse da maioria dos jovens em relação à leitura; a precariedade das bibliotecas escolares e; especialmente a carência de métodos adequados à formação literária dos alunos. Esta ausência de metodologias ficou evidenciada na falta de respostas a determinadas questões por parte de vários educadores entrevistados "Como despertar o interesse dos alunos frente à Internet? Como fazer com que os alunos tenham prazer em ler textos e livros?Como tornar a leitura interessante?" (Entrevista, CEMEPE, 2011).

Além desse hiato metodológico, os depoimentos apontam para uma lacuna na formação literária desses professores em relação ao gênero poético que, devido à sua complexidade e características peculiares, tem sido quase "banido" da sala de aula. Isso porque os docentes consideram complicado trabalhar com o aluno o sentido do texto (Entrevista, CEMEPE, 2011).

Questionados acerca da utilização da leitura em voz alta em sala de aula, vários professores afirmaram que a utilizam

[...] "para trabalhar a sonoridade das palavras";

[...] "para perceber o ritmo da poesia";

[...] "para se trabalhar oralidade";

[...] "para melhor compreensão do texto e para discussão" (Entrevista, CEMEPE, 2011).

Embora a maioria dos docentes dessa entrevista não tenha uma formação teórica em relação ao assunto, esses professores afirmaram realizar, eventualmente, um trabalho voltado para a oralidade. A prática da poesia em sala de aula não consiste, no entanto, em uma atividade diária, pois é realizada apenas em datas específicas, ou quando da execução de algum projeto da escola, o que confirma as colocações de Fares (2010), feitas anteriormente. 


\section{Revista do SELL}

v. 5 , no. 2

ISSN: $1983-3873$

Alguns professores reclamaram do pouco tempo que dispõem para incentivar os alunos à leitura, isto devido à preocupação de se cumprir o Programa Oficial de Língua Materna, o que leva por vezes a se privilegiar o ensino da língua. Destacamos alguns depoimentos desses docentes acerca do ensino de Literatura e de Língua Portuguesa:

"Acho que o nível de importância deve ser o mesmo, porém pelas exigências, e até por questões de necessidade, acaba-se priorizando o trabalho com a Língua Portuguesa".

"Ambos são importantes, mas os conteúdos da Língua Portuguesa, que permitem o uso social da língua de maneira eficiente e adequada, tem prioridade".

"Priorizo o ensino da Língua Portuguesa devido a cobranças e ao cumprimento do conteúdo programático, porém, particularmente, prefiro ensinar Literatura".

"Ideologicamente, valoriza-se mais gramática que Literatura. Nem sempre há espaço para dinâmicas lúdicas, freadas pela burocracia escolar e pelos muitos aspectos gramaticais que temos que abordar".

"O tempo é muito limitado e são necessárias escolhas, seleção de conteúdos, [...] no impasse de compromissos burocráticos - provas, projetos escolares"... (Entrevista, CEMEPE, 2011).

$\mathrm{Na}$ realidade, a inserção da Literatura nos Programas de Ensino não se condiciona exclusivamente às exigências curriculares, pois os programas são flexíveis. Além disso, há nos Currículos Básicos Comuns - os CBCs - um respaldo para se trabalhar com Literatura. Nada impede, portanto, que o professor o faça, organizando o tempo que dispõe de acordo com aquilo que considera prioridade. O problema é que esta primazia volta-se, frequentemente para o ensino da língua e da gramática, concepção esta advinda, possivelmente, da formação acadêmica da maioria desses professores.

Alguns depoimentos revelam uma tensão entre o jogo com regras da língua e o jogo aberto da poesia, que assinalam uma dupla filiação. De um lado há os docentes que defendem o prazer espontâneo e compartilhado da palavra poética, sendo favoráveis à falta de sistematização, programação e avaliação: "Valorizo muito o ensino de Literatura, acho que o gosto pela leitura fará diferença na vida dos alunos" (Entrevista, CEMEPE, 2011). 


\section{Revista do SELL}

v. 5 , no. 2

ISSN: $1983-3873$

Por outro lado, há aqueles que "acolhem o lúdico poético como motivação, mas o objetivo real é a análise e a apropriação das técnicas abordadas, [...] tratar-se ia de 'a imaginação a serviço' do poder do discurso" (COLOMER, 2009, p.176):

"A partir dos gêneros literários e textuais incentivo os alunos a reconhecerem os elementos constitutivos da língua".

"Ensino Literatura, porque os conteúdos da língua devem ser contextualizados nos textos literários ou não".

"Penso ser necessário trabalhar a Língua Portuguesa e dentro, as questões literárias" (Entrevista, CEMEPE, 2011).

Assim, verificamos que, de certa forma, há uma desvalorização da Literatura pelo sistema de ensino em geral e pelos próprios professores na avaliação da disciplina, quer seja esta qualitativa ou quantitativa. Percebemos também que em algumas escolas, atribui-se apenas conceito à matéria, em outras, a nota é atribuída como forma de punição ao desinteresse dos alunos, como se pode comprovar no depoimento a seguir:

"Em algumas escolas reserva-se 5,0 pontos para a Literatura, no total de 20 a 30 pontos, e soma junto com o Português e em outras, só conceito [...] a Literatura, sendo arte, deve ser só lúdica [...]. O aluno brinca muito nessas matérias que não tem nota - tipo Religião, Literatura, Artes. Dar nota é uma forma de amenizar esse problema [...] como uma forma de punir, porque se o aluno brinca, não faz as tarefas, perde nota. Então ajuda na disciplina dos alunos durante as aulas. Infelizmente é assim, como se Literatura não valesse nada" (Entrevista, CEMEPE, 2010).

Além da falta de motivação dos alunos em relação à disciplina Literatura, percebemos uma desmotivação por parte da maioria dos professores, certamente porque não desenvolveram, eles mesmos, o prazer pela leitura de poesia. Isso se torna, então, um círculo vicioso como mencionado anteriormente - os professores que não possuem gosto pela leitura de poemas, não conseguirão despertá-lo nos discentes, conforme evidencia-se no depoimento a seguir: "Minha maior dificuldade é encontrar a minha própria motivação pra ler poesias. Trabalho sim com esse gênero, mas falta a minha identificação e o meu gosto para tal” (Entrevista, CEMEPE, 2011).

\footnotetext{
${ }^{6}$ Optamos por colocar as falas dos entrevistados da pesquisa entre aspas, no corpo do texto quando for de até três linhas e, empregamos o recuo quando tratamos da fala de vários entrevistados sobre um mesmo assunto.
} 


\section{Revista do SELL}

v. 5 , no. 2

ISSN: $1983-3873$

Embora constitua uma minoria, percebemos que há alguns professores que dão destaque à poesia ou que a utilizam em projetos extraclasse, como é o caso de duas professoras entrevistadas por nós, que trabalhavam semanalmente com o texto lírico, nas aulas de Literatura do Ensino Fundamental. Outro caso é o de um professor da rede pública federal que, além de trabalhar a poesia na sala de aula, realizou uma oficina ${ }^{7}$ poética com alunos de $8^{\circ}$ e $9^{\circ}$ anos, também no Ensino Fundamental, em turno extraclasse.

Projetos pedagógicos envolvendo poesia poderiam ser mais recorrentes em nossas escolas, mas na rede estadual de ensino em Minas Gerais por exemplo, isso quase não acontece. Foi o que constatamos em nossa experiência docente nessa rede, ao longo de vinte anos em cidades mineiras, não só como professora, mas também em troca de experiência com outros educadores da escola pública estadual. Observamos que além da carga horária em sala de aula a ser cumprida pelo professor, há os chamados "módulos", que o docente cumpre com os estudantes, porém estes se destinam geralmente a aulas de reforço, ou à aplicação de testes aos alunos faltosos, sendo raramente voltados para projetos educativos.

Destacamos que os docentes da rede pública federal têm o seu trabalho em regime semi-integral, ou seja, são incentivados a desenvolverem projetos com os alunos fora do turno escolar, como esclareceu-nos W:

"No nosso plano de horário, a oficina está definida como projeto de ensino, acompanhamos 0 aluno fora do horário, oferecendo atividades paradidáticas, que aprofundam um determinado tópico, dentro do nosso trabalho, mas dentro do horário do professor, no semestre. [...] Na escola em que trabalho, é comum que os professores 'bolem' projetos de ensino para se desenvolver com os alunos" (W, Entrevista, 2011).

W reconhece as limitações do professor, quando se trata de trabalhar poesia, e estabelece diferenças fundamentais entre o seu trabalho em sala de aula e na oficina extraturno:

"A ideia da oficina é para os alunos terem um contato mais dinâmico com a
poesia do que eles têm na sala de aula, onde a poesia aparece como
mais um dos gêneros que vamos trabalhar. Por exemplo, trabalha-se as

\footnotetext{
7 Optamos por acompanhar o trabalho desse professor, que chamamos de $\mathrm{W}$ neste estudo para resguardar a sua identificação, em consonância com as normas do CEP - Conselho de Ética em Pesquisa. A descrição detalhada desse trabalho e sua análise encontra-se em nossa tese, aqui já mencionada.
} 


\title{
Revista do SELL
}

v. 5 , no. 2

ISSN: $1983-3873$

\begin{abstract}
características formais da poesia, a questão do ritmo, da sonoridade, da imagem verbal, das metáforas,[....] mas a gente faz isso de forma mais abreviada porque existem outros gêneros textuais [...]. As oficinas dão uma dinâmica ao trabalho com o texto poético especificamente, tanto na escrita como na leitura, pois temos um tempo maior para discutir livremente sobre esses textos, [...] um espaço de criação do texto poético que na sala de aula é muito mais restrito [...]. Além disso, o público da oficina é diferenciado porque tem um interesse específico. [...] Na sala de aula é mais complicado, você tem alunos que tem uma outra vivência, um interesse um pouco diferente, então a gente faz uma discussão mais restrita mesmo" [...] (W, Entrevista, 2011, grifos nossos).
\end{abstract}

Observamos através desse depoimento que nas aulas de Português/Literatura, a poesia é explorada, geralmente, de forma limitada, quer seja devido ao acúmulo de conteúdos que o docente precisa trabalhar, quer seja pela questão do interesse do aluno. Esta fala de W dialoga com o depoimento dos professores já especificados anteriormente, que em grande parte privilegia o estudo da língua materna em detrimento ao trabalho com poesia.

Concebemos que a motivação dos alunos por meio do texto poético pode ser alcançada, desde que o educador utilize metodologias interessantes e criativas em sala de aula. Nessas metodologias, a parceria da poesia com as artes, seja música, teatro ou arte visual tem oferecido bons resultados. É o que comprovam alguns projetos e pesquisas $^{8}$ realizadas por professores em sala de aula com o texto poético como, por exemplo, as dissertações de Mestrado de Paschoal (2009) e de Grossi (1999), e a tese de doutorado de Souza (2007), de Oliveira (2007), dentre outras.

Vale ressaltar que, nós também, em nossa experiência docente na rede pública estadual de ensino, enfatizamos o trabalho com poesia oral tanto no Ensino Médio como no Fundamental. Em 2014 realizamos um sarau literário na escola, finalizando o Projeto "Quirromantismo" - , onde os alunos apresentaram em performance direta $^{9}$, textos poéticos estudados em sala de aula. Também realizamos, em 2013, o projeto Nossa escola em versos, que envolveu cerca de 130 alunos dos $7^{\circ}$ e $8^{\circ}$ anos do Ensino

\footnotetext{
${ }^{8}$ Os dados completos desses trabalhos constam na referência desse estudo.
}

${ }^{9}$ De acordo com Zumthor (2007), performance direta consiste na atuação de um leitor real em contato com o ouvinte, também concreto, ou seja, essa performance implica uma presença sensorial do(s) indivíduos. Há também, segundo o autor, a performance indireta, em que falta um desses elementos e a performance em grau zero, quando a leitura é silenciosa. 


\section{Revista do SELL}

v. 5 , no. 2

ISSN: $1983-3873$

Fundamental e uma turma do $1^{\circ}$ ano EJA. Este projeto levou a poesia para o centro das atividades diárias dos alunos, sendo estes semanalmente, convidados a vocalizar ${ }^{10} \mathrm{o}$ texto poético e a se expressarem, produzindo poemas, que foram organizados para compor um livro ${ }^{11}$, cujo lançamento ocorreu durante um Recital Escolar.

O fato de trabalhos sistemáticos com poesia ocorrerem de forma tímida nas escolas brasileiras, muitas vezes se justifica, por um lado, pelas orientações do CBC, o Currículo Básico Comum, cujo conteúdo sugere que o professor de Língua Portuguesa contemple em seu conteúdo diferentes gêneros textuais. Todavia, nada impede que o gênero poético esteja associado a textos de diferentes gêneros. É mesmo aconselhável que a poesia apareça junto a outros estilos textuais e a várias linguagens artísticas para que o discente possa comparar, analisar e refletir sobre a diversidade textual.

Por outro lado, a escassez de práticas pedagógicas que privilegiem a poesia no dia a dia da sala de aula incide em uma concepção, há muito difundida em nosso meio cultural, que considera a arte - e a Literatura - como uma forma de divertimento, de alívio às tensões das outras disciplinas, consideradas mais "sérias". Devido a essa concepção, o aprendizado por meio da educação estética, como nos diz Grossi (2008), é frequentemente questionado, tanto pelo professor como pela própria escola. Para alguns docentes, constitui perda de tempo valorizar a disciplina literária, considerada supérflua, sentimentalista, conforme o depoimento de uma das professoras no CEMEPE: "Priorizo a Língua Portuguesa, pois o mundo em que vivemos está mais para prático do que para 'doce', o estudante deve ser melhor preparado para aquele do que para este" (Entrevista, CEMEPE, 2011. Grifos nossos).

Consequentemente, encontramos propostas metodológicas distintas nesse meio: enquanto alguns professores valorizam a expressão individual e espontânea do aluno, outros dão uma maior ênfase na introdução de conceitos ou de códigos artísticos. Há ainda aqueles que misturam essas duas linhas.

\footnotetext{
${ }^{10} \mathrm{O}$ termo vocalização refere-se à prática da leitura expressiva em que o leitor imprime ao texto uma significação, por meio da voz e, por declamação entende-se a leitura em voz alta de poesia.

11 Trata-se da coletânea poética "Nossa escola em Versos", um livro financiado pelo PDE - Plano de Desenvolvimento Escolar, lançado em 2013.
} 


\section{Revista do SELL}

v. 5 , no. 2

ISSN: $1983-3873$

Com essas distintas posturas, nem sempre a oralidade poética ocupa um lugar de destaque no contexto escolar. Apesar disso, de maneira geral, o trabalho sistemático com a oralidade poética acompanhado em nossa pesquisa - assim como os projetos poéticos desenvolvidos em nossa experiência docente - promoveu de fato, benefícios significativos aos alunos.

Em primeiro lugar, a leitura de poesia funcionou, na maioria das vezes, como forma de motivação para a leitura literária, permitindo assim, o diálogo intertextual. Nesse sentido, foi de fundamental importância o papel do professor, que ao vocalizar os poemas, não só cultivou o diálogo sobre os textos propostos, mas pôde também trazer à cena outros textos e poemas, por meio dos quais buscou ampliar o horizonte de expectativas dos jovens aprendizes.

Essa experiência foi comprovada na oficina poética, quando a oralidade constituiu um instrumento fundamental do docente para incentivar os alunos a lerem não apenas determinada antologia, mas a irem além, buscando outras leituras. Além disso, nas oficinas do professor $\mathrm{W}$, a oralidade poética motivou os jovens alunos ao exercício da escuta sensível que, por sua vez, permitiu-Ihes aflorar uma série de conhecimentos intuitivos que não surgem ao nível da racionalidade, e que são importantes para que os leitores possam preencher os vazios do texto, fazendo as associações necessárias a sua compreensão. Sendo assim, pode-se afirmar que a poesia oral contribui para que o aluno/leitor possa interpretar o(s) texto(s) de forma mais aprofundada, ampliando as suas habilidades leitoras.

Em segundo lugar, o trabalho com oralidade poética permitiu aos estudantes vivenciarem a situação concreta da performance - por meio do corpo, em sua plenitude quando da realização do Recital e do Sarau de poesias na escola, em consonância com a teoria de Zumthor (2007, p. 18), para quem "toda literatura é fundamentalmente teatro". Nessa situação, ficou comprovada a interação entre aqueles que executaram o poema e aqueles que o receberam pela audição, concomitantemente - devido à força da recepção desses textos - quando deixaram de ser uma expressão individual dos jovens discentes para se transformarem, em uma expressão coletiva, por meio da oralidade poética. 


\section{Revista do SELL}

v. 5 , no. 2

ISSN: $1983-3873$

Em terceiro lugar, constatou-se que o gosto pela leitura de poesia e pela sua performance pode ser cultivado em qualquer faixa etária e em qualquer série.O grande interesse das turmas de EJA - Educação de Jovens e Adultos - quando na realização do Sarau Literário e do livro de Poesias comprovou-nos esta realidade. Possivelmente, essa experiência confere a sua marca ao sujeito, contribuindo no seu processo de formação de leitor literário; processo este que o acompanhará por toda a vida, ultrapassando o espaço escolar.

\section{Considerações finais}

A pesquisa realizada com um grupo de professores uberlandenses da rede pública veio a confirmar que, por um lado, alguns docentes tendem a não utilizarem a poesia em sala de aula. Por outro lado, observamos certa tendência à utilização prática do texto poético, de acordo com uma abordagem metodológica voltada, frequentemente, para o texto escrito, utilizado pelo professor com fins de metaleitura ou para estudos gramaticais. Comprovou-se pela investigação que a maioria dos docentes pesquisados prioriza o ensino da língua e de gramática, concepção esta oriunda, certamente, da formação acadêmica desses profissionais.

Essas práticas evidenciaram, muitas vezes, a existência de uma lacuna ou falha no embasamento teórico-metodológico dos professores em relação à Literatura, bem como em relação às poéticas orais. Tal lacuna, já destacada por Feitosa (2008) impede esses professores de valorizarem, em sua prática cotidiana, o texto poético numa perspectiva mais lúdica e prazerosa,visto que, poucos docentes trabalham com a poesia na escola quer seja em sala de aula ou em projetos extracurriculares.

Por meio da articulação entre os conceitos abordados e a prática escolar adotada pelo professor da rede pública no projeto Oficina de Leitura e Produção de Textos Poéticos, bem como pela nossa própria experiência docente, observamos a importância do fenômeno da oralidade poética e da aplicação dos conceitos levantados nessa pesquisa em vários aspectos, quais sejam: como forma de motivação para a leitura literária, por permitir a intertextualidade e a escuta sensível ao aluno, por proporcionar a experiência da performance e por influenciar na recepção do texto, dentre outras. 


\section{Revista do SELL}

v. 5 , no. 2

ISSN: $1983-3873$

Em virtude dessa relevância, sugerimos aos mediadores e profissionais da educação que a utilização de metodologias que focalizem a poética oral - exemplificada e analisada por meio dos fenômenos que compõe nossa investigação - ocorra com mais frequência no ambiente formal de educação e cultura. Esperamos, por meio desse estudo, somar esforços, junto a outros pesquisadores, que se empenham para uma valorização das poéticas orais no contexto escolar.

\section{Referências}

BAJARD, Elie. Ler e dizer: compreensão e comunicação do texto escrito. 5 ed. São Paulo: Cortez, 2005.

BORDINI, Maria da Glória. Estudos culturais e estudos literários. Revista Letras de Hoje, Porto Alegre, v. 41, n. 3, p. 11-22, set., 2006. Disponível em:

$<$ http://revistaseletronicas.pucrs.br/ojs/index.php/fale/article/viewFile/610/441>. Acesso em: 15 jan. 2011.

BRAZ, Gláucia Helena. A performance do leitor diante da oralidade poética: passagens de indecisão.2012. Dissertação (Mestrado). Instituto de Letras e Linguística da Universidade Federal de Uberlândia, Universidade Federal de Uberlândia, Uberlândia, 2012. . (org.) Nossa escola em versos.Uberlândia: Edibrás. 2013.

CANDIDO, Antônio. O direito à literatura, In CANDIDO, Antônio. Vários escritos, $4^{\underline{a}}$ ed. São Paulo: Duas cidades; Rio de Janeiro: Ouro sobre Azul. 2004.

COLOMER, Teresa. Andar entre livros: A leitura literária na escola. Tradução de Laura Sandroni. São Paulo: Global, 2009.

FARES, Josebel Akel. Oralidade e educação. Poéticas orais em sala de aula: relatos e retratos. In: SEMINÁRIO BRASILEIRO DE POÉTICAS ORAIS: VOZES, PERFORMANCES, SONORIDADES I., 2010, Londrina. Anais... Londrina: Universidade Estadual de Londrina - UEL,2010. p. 264 - 279.

FARIA, Vanessa Fabíola Silva de. O ensino de literatura e a formação do leitor literário: entre saberes, trajetórias de uma disciplina e suas relações com os documentos oficiais. Universidade Estadual de Mato Grosso. Revista Iberoamericana de Educación, [S.I.: s.n.] n. 49/7, 2009. Disponível em: <http://www.rieoei.org/deloslectores/2801Faria.pdf >. Acesso em 14 set. 2011.

FEITOSA, Márcia Soares de Araújo. Prática docente e leitura de textos literários no fundamental II: uma incursão pelo programa Hora da Leitura. Dissertação (Mestrado) Faculdade de Educação, Universidade de São Paulo, São Paulo, 2008. 


\section{Revista do SELL}

v. 5 , no. 2

ISSN: $1983-3873$

FERREIRA, Jerusa Pires. Cultura das Bordas: Edição, Comunicação, Leitura. Cotia: Ateliê Editorial, 2010.

GROSSI, Maria Auxiliadora Cunha Grossi. Elementos para uma pedagogia do poético:métodos e práticas para uma comunicação dos sentidos. 1999. Dissertação (Mestrado) - Faculdade de Educação da Universidade de São Paulo, São Paulo, 1999.

.Literatura e Informação estética: a oralidade pelas vias da poesia e da canção e seus usos na educação. 2008. Tese (Doutorado) - Faculdade de Educação da Universidade de São Paulo, São Paulo, 2008.

LEITE, Eudes Fernando; FERNANDES, Frederico (Orgs.). Oralidade e Literatura: Outras veredas da voz. 3. ed. Londrina: EUEL, 2007.

VIEIRA, Harlei Cursino. Literatura no Ensino Médio: uma proposta pedagógica. Disponível em: <http://professorharlei.blogspot.com.br/2008/12/literatura-no-ensino-mdiouma-anlise.html>. Acesso em: 10 ago. 2011.

OLIVEIRA, Maria Alexander de. A Literatura para crianças e jovens no Brasil de ontem e de hoje: caminhos de Ensino. 2007. Tese (Doutorado) - Faculdade de Educação, Universidade de São Paulo, São Paulo, 2007.

PASCHOAL, Sônia Barreto de Novaes. Mediação cultural dialógica com crianças e adolescentes: oficinas de leitura e singularização, 2009. Dissertação (Mestrado) - Escola de Comunicações e Artes, Universidade de São Paulo, São Paulo, 2009.

SOUZA, Gláucia Regina Raposo de. Uma viagem através da poesia: vivências em sala de aula. 2007. Tese (Doutorado) - Faculdade de Educação, Universidade Federal de Porto Alegre, Porto Alegre, 2007.

TODOROV, T. A literatura em perigo. Rio de Janeiro: DIFEL, 2009.

ZUMTHOR, Paul.Performance, recepção, leitura. Tradução de Jerusa Pires Ferreira e Suely Fenerich. 2. ed. rev. e amp. São Paulo: Cosac \&Naify, 2007. 


\section{Revista do SELL}

v. 5 , no. 2

ISSN: $1983-3873$

\section{ANEXO}

Formulário destinado aos professores de língua Portuguesa e Literatura do Ensino Básico e Fundamental da rede pública de Uberlândia:

1-Em que série você atua?

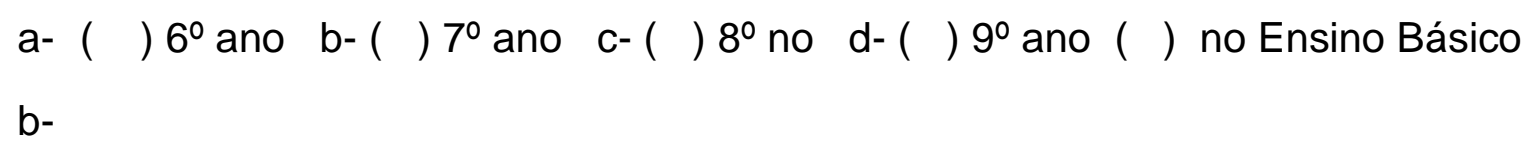

2- Você possui formação específica em Literatura? Qual?

3- Avalie de 1 a 5 de acordo com a frequência que você costuma trabalhar os seguintes gêneros textuais em sala de aula:
a. ( ) fábulas
b. ( ) contos
c. ( ) crônicas
d. ( ) poesias
e. ( ) música
f. ( ) textos para teatro
g. ( ) romances
h. ( ) histórias em quadrinhos

4. Com que frequência você trabalha poesia?
a- ( ) uma vez por semana
C- ( ) uma vez ao mês
b- ( ) raramente
d- ( ) mais de uma vez por semana

5. No trabalho com poesia, o poema é lido em voz alta em sala de aula
a- ( ) sempre que trabalho com poesia
b- ( ) às vezes
c-( ) raramente.

6-O objetivo de se trabalhar com Literatura é:

a- ( ) fixar conhecimentos da língua, sejam ortográficos ou gramaticais

b- ( ) para se trabalhar leitura e análise de texto

c- ( ) para sensibilização do aluno para o gosto pela leitura

d- ( ) para se incentivar a leitura e a produção de textos 


\section{Revista do SELL}

v. 5 , no. 2

ISSN: $1983-3873$

6.1- Em sua escola, ocorre a interdisciplinaridade, ou seja, o trabalho conjunto com outra(s) disciplinas?

a- ( ) sim b- ( ) não c- ( ) raramente

6.2- Em caso afirmativo, com quais matérias e com que frequência?

7- O trabalho com poesia consta no seu programa curricular? E com música?

8-Você considera mais importante ensinar os conteúdos da Língua Portuguesa ou ensinar Literatura? O que se prioriza no ensino de Literatura? Por quê?

9.1- As leituras literárias propostas aos alunos são de caráter: livre, ou previamente escolhidas pelo professor?

9.2- Se forem previamente escolhidas, quais são os critérios utilizados para essa escolha?

10-Há uma preocupação com os processos seletivos ao se trabalhar Literatura? A partir de que série?

11-Trabalha-se com teorias e conceitos literários? Como isso é realizado?

13-Quais os problemas enfrentados pelo professor no desafio de formar leitores de leitura literária, em geral?

14-Em se tratando da formação do leitor de poesia, quais são as dificuldades do professor? 